\title{
COVID-19, Teaching, and Service: The Challenge of Nursing Training Practices
}

Covid-19, docencia y servicio: el reto de las prácticas formativas en enfermería

\section{Covid-19, ensino e serviço: o desafio das práticas pedagógicas em} enfermagem

\section{Sonia Patricia Carreño-Moreno'}

KEYWORDS (SouRce: DeCS)

Education; nursing; practical nursing; nursing schools; nursing students; coronavirus infections.

PALABRAS CLAVE (FueNte: DeCS)

Educación en enfermería; enfermería práctica; facultades de enfermería; estudiantes de enfermería; infecciones por coronavirus.

PALAVRAS-CHAVE (Fonte: DeCS)

Educação em enfermagem; enfermagem prática; escolas de enfermagem; estudantes de enfermagem; infecções por coronavirus.

DOI: 10.5294/aqui.2021.21.2.1

To reference this editorial / Para citar este editorial / Para citar este editorial

Carreño-Moreno SP. COVID-19, Teaching, and Service: The Challenge of Nursing Training Practices. Aquichan. 2021;21(2): e2121. DOI: https://doi.org/10.5294/ aqui.2021.21.2.1

$1 \bowtie$ https://orcid.org/0000-0002-4386-6053. Associate Professor, Nursing School, Universidad Nacional de Colombia. Cuidado de Enfermería al Paciente Crónico Research Group. Colombia. spcarrenom@unal.edu.co. 
The COVID-19 pandemic has jeopardized not only global health, the economy, and politics but also education (1). Mainly, health sciences programs have suspended on-site practical experiences in hospital and community settings (2). The fear of possible contagion, the uncertainty about how the training processes could take place in risky environments, and the regulations that some countries such as Colombia issued restricting the training of health workers prevented nursing students from having onsite practice for almost a year. This paper aims to discuss the situation of nursing students regarding their return to nursing training practices in the context of the COVID-19 pandemic, the challenges, and potential strategies for such practices amidst the teaching-service relationship.

The pandemic has had a significant impact on the academic nursing community. A study conducted in Colombia in which I participated (in press activities), with more than 1,600 nursing students and recent graduates involved, revealed that, although the participants had adequate knowledge, attitudes, and practices regarding COVID-19, the prevalence of stress and fear was high. These findings concur with those in Mexico in a sample of 912 students (3); it was observed that stress and fear are correlated, and both increase with limited knowledge. Both studies noted a significantly higher prevalence of fear and stress due to COVID-19 than reported in other research conducted in the Philippines, Bangladesh, New Zealand, and Turkey (4). These results point to the first challenge: returning on-site training practices under vulnerable mental health conditions for students.

With the antecedent of affected mental health for students and, of course, professors, we faced the return to on-site training practices and all kinds of additional challenges presented. Issues such as the type and quantity of personal protection equipment and the responsibility for its provision and distribution; the concentration of students per patient or per available area in square meters; the internal epidemiological surveillance system; the procedure in case of contact with or occurrence of suspected cases; the type and material of the uniforms to be worn on the street and at practice sites; the type of adequate contact among students and between them and the professor, health team, and patients; the management of students with comorbidities; collective mental haze, among others, are some examples of everyday problems during the return to nursing training practices. However, despite the challenges, the continuous review of research results, shortterm planning and assessment, adherence to contagion prevention protocols, and flexibility have allowed rising to them gradually but firmly. All this resulted from collaborative work between aca- demia and care, which have joined efforts to guarantee not only service to the population but also the training of competent nurses for current demands.

After three months of my first training experience in a pandemic, I reaffirm that it is time to take advantage of the crisis to rethink nursing training. At a time that calls for flexibility, remote teaching supported by virtual and augmented reality, and simulated practice (5), I would add the need to maintain on-site practice under the premises of flexibility, autonomy, and innovation. The opening, adaptation, and adjustment of the curricula and the teaching-service relationship are imperative. Let us not lose sight of the obligation we have, as academia, to train competent professionals to cater to the needs of our population. At present, we have a unique opportunity to train a nursing force that, in the future, will be sensitive to actual problems. Therefore, we need to combine various practice alternatives that ensure clinical judgment and technical, critical thinking, and problem-solving skills. It is essential to open up to the possibility of on-site and remote simulated practice, practice in telehealth programs, and, of course, strengthening on-site practice. The alternatives mentioned are not the only ones, but they are a good starting point.

In the United Kingdom (1), for instance, given the limitation of on-site practice settings, nursing students, at their discretion, have had the chance to do their training practices in the health services available for the pandemic. This initiative enabled students to add their training activities to the system's efforts to contain the pandemic and continue comprehensive care for the entire population. Clearly, the initiative entails risks and challenges but is an alternative that has responded to the contingency of training future professionals and the deficit of nurses in these times. Rather than replicating this proposed practice, the invitation is to consider each of our contexts and devise flexible strategies that guarantee students' skills. Of the British proposal, I highlight the deference granted to the student's autonomy to opt for this practice model, so I urge academia to promote practical exercises that strengthen such autonomy.

In conclusion, today, when most of the world has prevailed over the third wave of infections, with limited on-site practice environments and a new lockdown, I emphasize the pressing need to stop and review the traditional forms of practice in our profession, consider the opportunities that the conjunction has given us, and reinvent nursing skills training. Nursing professors are called to take these actions in our role as agents for change in times of crisis (6). 


\section{References}

1. Haslam MB. What might COVID-19 have taught us about the delivery of Nurse Education, in a post-COVID-19 world? Nurse Educ Today. 2021; 97:104707. DOI: https://doi.org/10.1016/j.nedt.2020.104707

2. Yancey NR. Disrupting Rhythms: Nurse Education and a Pandemic. Nurs Sci Q. 2020; 33(4):299-302. DOI: https://doi. org/10.1177/0894318420946493

3. Medina Fernández IA, Carreño Moreno S, Chaparro Díaz L, Gallegos-Torres RM., Medina Fernández JA, Hernández Martínez EK. Fear, Stress, and Knowledge regarding COVID-19 in Nursing Students and Recent Graduates in Mexico. Investigación y Educación en Enfermería, 2021; 39(1):1-12. DOI: https://doi.org/10.17533/udea.iee.v39n1e05

4. Gohel KH, Patel PB, Shah PM, Patel JR, Pandit N, Raut A. Knowledge and perceptions about COVID-19 among the medical and allied health science students in India: An online cross-sectional survey. Clin Epidemiol Glob Heal. 2020; 9(1):104109. DOI: https://doi.org/10.1016/j.cegh.2020.07.008

5. Agu CF, Stewart J, McFarlane-Stewart N, Rae T. COVID-19 pandemic effects on nursing education: looking through the lens of a developing country. Int Nurs Rev. 2021; 68(2):153-158. DOI: https://doi.org/10.1111/inr.12663

6. Klar RT. Nurse Educators as Agents of Change in the SARS-CoV-2 Pandemic. Nurs Womens Health. 2020; 24(4):253-5. DOI: https://doi.org/10.1016/j.nwh.2020.05.010 